Derleme

\title{
GELENEKSEL BİR ÜRÜN OLARAK “MİDYE DOLMA” VE GELECEK ÖNERÍLERİ
}

As a traditional food "stuffed mussel" (Midye Dolma) and its future aspect

Doç.Dr. Zayde AYVAZ

Çanakkale Onsekiz Mart Üniversitesi

Deniz Bilimleri ve Teknolojisi Fakültesi

ÇANAKKALE

zaydealcicek@gmail.com

ORCID : 0000-0002-8102-0577

Gönderilme Tarihi: 5 Kasım 2018

Kabul Tarihi : : 15 Kasım 2018

\section{ÖZET}

$\mathrm{Su}$ ürünleri besleyici özellikleri ile öne çıkan bir gıda maddesidir. Bu kaynağa erişimin arttırılması için üretimin artmasının yanında tüketiciye ulaştırılma biçimlerinin de geliştirilmesi ve gıda güvenliği prosedürlerine uygun hale getirilmesi beklenmektedir. Bir kabuklu su ürünü olan midye, çeşitli şekillerde işlenerek değerlendirilmektedir. Pek çok ülkede oldukça popüler olan midye, finansal açıdan yüksek getirisi olan bir kaynaktır. Midye dolma Türkiye'de sokak yemeği kültürünün önemli bir parçasıdır. Ancak yapılan çalışmalara göre sokakta satılan midye dolmaların bir kısmı mikrobiyal yük açısından kabul edilebilirlik sınırların üzerindedir. Bunun en önemli nedenleri, kontrolsüz toplayıc1lı ve üretimdir. Tüm bu olumsuzlukların giderilmesi için, kontrollü şartlarda yetiştiricilik ve üretimin yapılması elzemdir. Bu çalışma; midye dolma açısından midye etine erişim ve işleme prosesleri hakkında mevcut problemler ve gelecek önerilerini kapsamaktadır.

Anahtar Kelimeler: Midye, Midye dolma, Kontrollü midye yetiştiriciliği, Midye işleme 
ABSTRACT

Aquatic products are foodstuff that stands out with its nutritive properties. In order to increase access to this resource, it is expected that the ways of delivering to consumers as well as increasing production will be improved and adapted to food safety procedures. Mussels, which are a shellfish, are processed in many ways. Mussels, which are very popular in many countries, are a source of high financial gain. Stuffed mussels are an important part of the street food culture in Turkey. However, according to the studies, a portion of stuffed mussel sold on the street is above the acceptable limits in terms of microbial load. The most important reasons for this are uncontrolled gathering and production. In order to eliminate all these problems, aquaculture and production under controlled conditions is essential. This study covers current problems and future suggestions about access and processing of mussel meat in terms of stuffed mussels.

Keywords: Mussel, Stuffed mussel, Mussel aquaculture, Mussel processing

\section{GÍRİŞ}

Su ürünleri kaliteli hayvansal protein kaynaklarından biridir. Kabuklu su ürünleri lezzeti ve tercih edilebilirliği yüksek bir gıda maddesidir. Midye, Mytilae ailesine dahil çift kabuklulardandır. Atlantik kıyılarında, Akdeniz, Karadeniz, Marmara Denizi ve Boğazlar'da toplanarak avcılığı yapılmaktadır. Midye prehistorik çağlardan beri tüketilen bir gıdadır ${ }^{1}$. Ülkemizde yaygin olarak tüketilen midye, Akdeniz Midyesi Mytilus galloprovincialis'dir ve kara midye olarak da adland1rılır. Boyutları 6-8 cm arasındadır. Tüketim dönemleri ise, her mevsim tüketilebilmekle beraber, yaz aylarında tüketim oranları düşmektedir. Bunun en önemli nedeni, su sıcaklığının artarak zararlı mikroorganizmaların midye gibi süzerek beslenen canlıların etinde daha fazla bulunmasıdır ${ }^{2}$. Midye hem pişmiş hem taze olarak tüketilebilen yüksek besin değerine sahip bir kabukludur. Midye eti protein oranı yüksek, yetiştiriciliğe uygun bir çift kabuklu türüdür. Kuru ağırl1ğının \%60'ına kadarı proteinden oluşur. Yağ oranı ve kolesterol seviyesi düşüktür. A, B1, niasin, B2, C,D ve E vitaminleri ile Demir ve Kalsiyum elementlerini

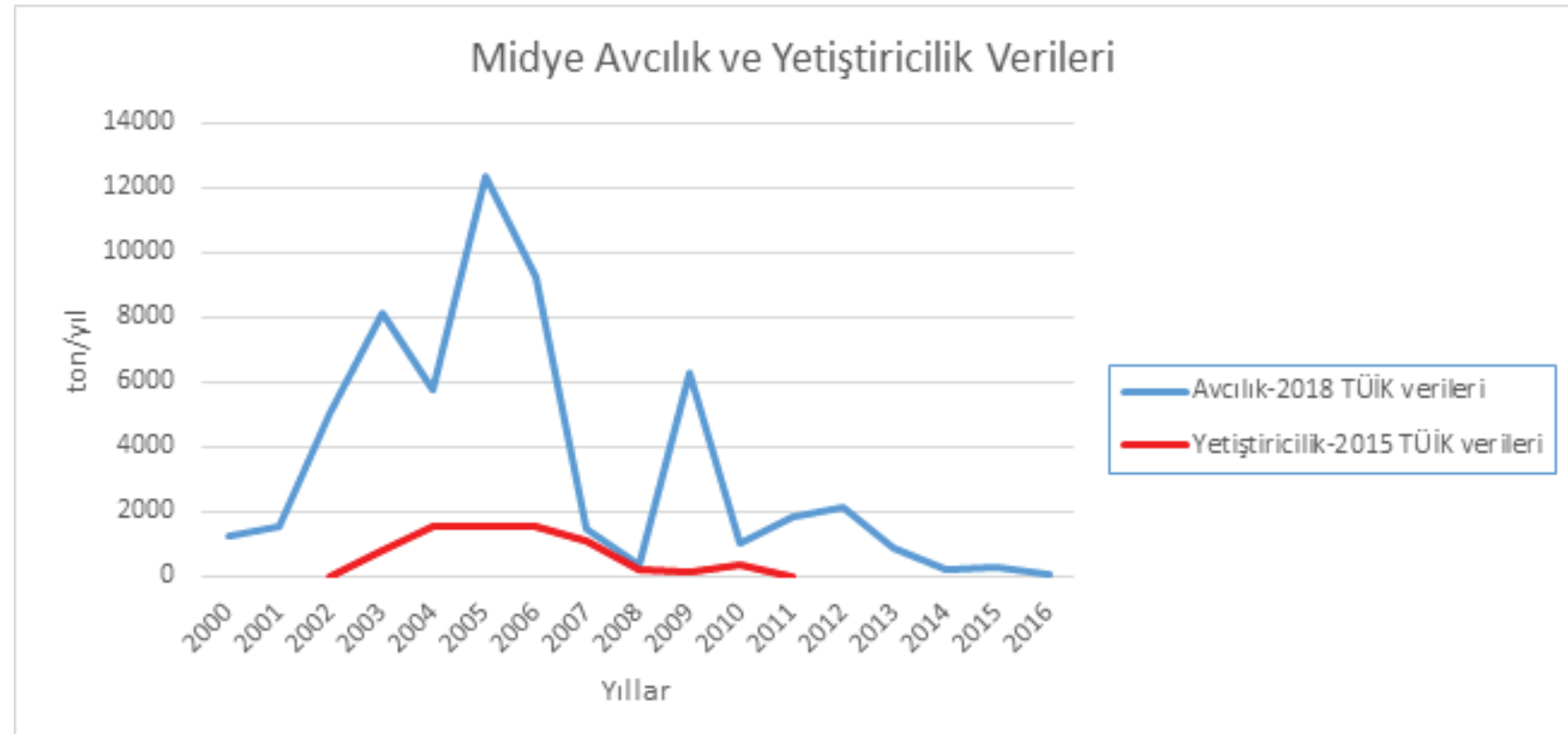

Çizelge 1: Yıllara göre midye avcılık ve yetiştiricilik verileri 5,6 
de içerir ${ }^{3}$. Midye yetiştiriciliği Avrupa'da yaygın olmakla birlikte Ülkemizde 2011 yılından sonra TÜİK'e gelen yetiştiricilik verileri bulunmamaktadır (Çizelge 1). Kalkınma Bakanlığı'mızın 10. Kalkınma Planında ise midye yetiştiriciliğinin maddi nedenlerden dolayı bitme noktasına geldiği vurgulanmıştır .

\section{Midye Dolma}

Midye dolma, Ülkemizde geleneksel, tüketime hazır olarak satılan bir mezedir. Görkem ${ }^{7}$ midye dolmayı "ulusal fastfood" olarak nitelendirmiştir. Midye dolmanın gastronomi kültürüne girişi Osmanlı Devleti'nin İstanbul'u fethini takiben gerçekleşmiştir. Bu dönemde pek çok deniz ürününe ait yemek biçimleri yeme kültürümüzün parçası olmuştur ${ }^{8}$. Basılmış ilk Türk yemek kitabı olan 'Melceü't-Tabbahin (1844-Mehmet Kamil)" (Aşçıların Sığınağı)'de midye dolma tarifi "Dokuzuncu Fasıl- Zeytinyağlı ve sağyağlı dolmalar" bölümünde "Midye Dolması" olarak tarif edilmiştir". Günümüzde bir "sokak yiyeceği” (street food) ${ }^{10}$ olarak midye dolmanın içeriği; haşlanmış kabuklu midye içi ile haşlanmış pirinç ve çeşitli baharatlarla hazırlanmış iç pilavdır. Tüketim oranları istatistik açıdan tam olarak bilinemez. Bunun en önemli nedeni kayıt diş11ıktır. Midye avcılığı, toplayıcılık yoluyla gerçekleştirilir. Toplanmış midyeler çuvallar vasıtasıyla taşınırlar ve üretim yerlerine kolaylıkla aktarılabilirler. Bu durum kayıt dışılığı önemli oranda arttırmaktadır. Kayıt işlemleri yetiştiricilik yapıldığında daha etkin biçimde takip edilebilir. Ancak ülkemizde yetiştiricilikten gelen veriler 2012 yılında sonlanmıştır ${ }^{5}$ ve bu yılda kilogram başına üretim desteği $0,20 \mathrm{TL} / \mathrm{kg}$ olarak sunulmuştur ${ }^{4}$. Kayıt dışılığın birincil dezavantajı, midye gibi yetiştiği yere bağli olarak, mikrobiyolojik yük ve ağır metal içeriği bakımından tehlike arz edebilecek süzücü canlıların tüketimi sonucu, insan sağlı̆̆1 açısından kontrolünü güçleştirmesidir. Midyeler organik atıkların olduğu alanlarda gelişebilir. Genellikle bu alanlar kıyıya yakın kesimlerdir. Bu durum toplayıcılar için oldukça cazip olabilir. Toplayıcılık dışında, midye, kontrollü biçimde uygun yerlerden hasat edilerek depürasyon işlemine tabi tutulup zararlı içeriğinden arındırılabilir. $\mathrm{Bu}$ midyeler de yine midye dolma üretimi yapan bazı üreticilerce kullanılmaktadır. Bu teknikle üretilen ve dondurulmuş olarak satılan midye içi de marketlerde kolaylıkla satın alınabilmektedir. Ancak dondurulmuş midyelerin bir kısmı yurtdışından özellikle Avrupa'dan ithal edilmektedir.

Sokak yemeği kültürünün önemli bir parçası olarak midye dolma ile ilgili yapılan çalışmalara göre sokakta satılan midye dolmaların bir kısmı mikrobiyal yük açısından kabul edilebilirlik sınırların üzerindedir ve bunun en önemli nedenlerinin ise kontrolsüz toplay1cılık ve üretim ile pişirme sonrası satış esnasında yaşanan sıcaklık dalgalanmaları olduğu düşünülmektedir ${ }^{11}$.

Listeria türleri gida kaynaklı patojenlerden biri olan Listeria monocytogenes'i de ihtiva eder ve listeriyozis isimli bir hastalığa neden olur. Şireli ve Gücükoğ$1 u^{11}$, Ankara ilinde satılan hazır gidaların Listeria spp. açısından varlığı ve antibiyotik dirençleri hakkında yaptıkları çalışmada, midye dolmalarda Listeria spp., L. innocula ve L. grayi'yi izole ettiklerini belirtmişlerdir. Buna göre analize dâhil olan örneklerin $\% 5$ 'i Listeria spp. açısından pozitif sonuç vermiştir. Bu oldukça önemsenmesi gereken bir orandır. Yine Göksoy ve ark. ${ }^{12}$ yaptıkları çalışmada, midye dolmada bulunan Listeria monocytogenes'in tanısı için iki farklı yöntem kullanmışlardır. Sonuç olarak kullandıkları yöntemlerden birinde 50 örnekten 5 'inde pozitif veri elde etmişlerdir. Araştırmacılar bu tarz sokak yiyeceklerinin hiçbir önlem olmadan satılmasının ciddi gıda kaynaklı hastalıklara ya da zehirlenmelerine neden olacağını bildirmiştir. Terzi ve ark. ${ }^{13}$ ise Samsun ilinde satılan midye dolmalarda Listeria monocytogenes araştırmışlardır. Aldıkları 25 örnekte de bu türe rastlanmamıştır. $\mathrm{Bu}$ türe rastlanmamış olması midyenin toplandığ 1 yer ve midye dolmanın hazırlanma koşulları ile ilgili olduğu bildirilmiştir. Koliform bakteriler insan/hayvan dişkısı veya bitki/toprak kaynaklı olabilmektedir. Gıdalarda E. Coli dışındaki fekal koliformları inceleyen bir çalışmada ise midye dolmanın da bulunduğu örnekle- 
melerde pek çok fekal koliform analiz edilmiştir ${ }^{14}$.

Ateş ve ark. ${ }^{15}$, sokakta satılan midye dolmada çeşitli mikrobiyolojik analizler (Bacillus cereus, Staphylococcus aureus, Escherichia coli, Salmonella sp., Clostridium sp.) yaptıkları çalışmada; analiz ettikleri ürünlerin \%50'sinin, Salmonella sp. (gibi gıda kaynaklı hastalıklarda en çok rastlanan tür) açısından tüketilemez olduğu sonucuna ulaşmıştır. Yine diğer türler açısından da Türk Gıda Kodeks'inin belirlediği sınırların üzerinde olduğu pek çok örneğe rastlamışlardır. Sonuç olarak araştırmacılar, sokakta satılan midye dolmanın insan sağlığını tehdit edebileceğini vurgulamıştır. Öneri olarak ise daha iyi koşullarda pişirme, dağıtım şartlarını sunmuşlardır. Araştırıldığı kadarıyla, literatürde kendi hazırladıkları midye dolmaların paketlenerek muhafazası ve muhafaza süresince değişimlerin incelendiği tek çalışma Ulusoy ve Özden ${ }^{16}$ ' in yaptığ1 çalışmadır. Araştırmacılar farklı gaz karışımları kullanarak modifiye atmosfer paketleme (MAP) tekniği ile hazırladıkları midyeleri depolamışlardır. $\mathrm{Bu}$ çalışmada amaç MAP'ın etkinliğini ortaya koymaktır. Mikrobiyolojik açıdan mesofilik bakterilerin zaman içinde arttığını bulmuşlardır. Bingöl ve ark. ${ }^{3}$, İstanbul'da satılan midye dolmaların mikrobiyolojik kalitesini Türk Gıda Kodeksine uygunluğuna göre incelemiştir. İncelenen örneklerin \%77,38'inde koliform bakterileri, \%22,02'sinde E. coli, \%23,8'inde Staphylococcus aerous, \%38,69'unda Bacillus cereus tespit edilmiştir. Genel aerobik bakteriyel yükün ise $1.0 \times 10^{2}$ olduğu belirtilmiştir. Bu bağlamda İstanbul ilinde satılan midye dolmaların gida zehirlenmesi ya da gida kaynaklı hastalıklara neden olması beklenmektedir.

\section{Midye işlemede Dünyadan örnekler ve gelecek öne- rileri}

Midye yetiştiriciliği Avrupa ülkelerinde yaygın olarak yapılmaktadır. Ülkemizde yetiştiricilik koşulları Avrupa standartlarına ulaştırılarak gerçekleştirilebilirse Avrupa midye pazarı önemli bir ihracat pazarı olarak değerlendirilebilir. Yanı sıra; Ülkemizdeki midye tü- ketiminde başlica tüketilen midye yemeklerini, yemeye hazır birer ticari ürün olarak üretip marketlerde derin dondurucularda ya da buzdolaplarında veya raflarda satılan ambalajlı ürün olarak pazarlanmasını sağlayarak, iç pazarda da güçlü bir tüketim oranı elde edilebilir. $\mathrm{Bu}$ güçlü potansiyelin kullanılması ülke ekonomisine önemli bir girdi sağlayacaktır. Bunu ülkesinin en önemli kaynaklarından biri haline getiren Yeni Zelanda örneği güçlü bir emsaldir (19. yy'dan beri) $)^{17,18,19}$.

Tablo 2: Bir örnek olarak Fransa'da pişirilen en yaygın midye yemekleri (Monford, 2000'den çevirilmiştir) ${ }^{17}$

\begin{tabular}{|l|l|}
\hline Yemeğin adı & İçeriği (midye ile) \\
\hline A la marinière & $\begin{array}{l}\text { Soğan, tereyağı, beyaz şarap, kere- } \\
\text { viz, maydanoz }\end{array}$ \\
\hline À la crème & $\begin{array}{l}\text { Kereviz, soğan, krema, beyaz şa- } \\
\text { rap }\end{array}$ \\
\hline À la provençale & $\begin{array}{l}\text { Domates, sarımsak, soğan, beyaz } \\
\text { şarap, tereyağ } 1\end{array}$ \\
\hline $\begin{array}{l}\text { Au beurre d'es- } \\
\text { cargot }\end{array}$ & Sarımsak, tereyağ1, maydanoz \\
\hline $\begin{array}{l}\text { Au curry } \\
\text { Krema, köri, maydanoz, beyaz şa- } \\
\text { rap }\end{array}$ \\
\hline
\end{tabular}

Avrupa'da üretilen toplam midye miktarı tahmini olarak 700 bin ton/y1l'dır ${ }^{17}$. Avrupa'da canlı midye ihtiyac1, yerel yetiştiricilerin yüksek oranda üretimleri ile karşılanmaya çalışılmasına rağmen hala daha fazlasına ihtiyaç duyulmaktadır. Bu ihtiyaç gitgide artarak ilerlemektedir. Daha fazla üretim yapılmasını engelleyen başlica nedenler, Avrupa'daki en önemli üreticisi ve sağlayıcılarından biri olarak Fransa örneği (Tablo 2) için şöyle sıralanmıştır:

- Fransiz kiyılarının tamamı, hali hazırda var olan balık çiftlikleri, avcılık stoklarının önemli oranda sömürülmüş olması ve diğer ekonomik aktiviteler ile kullanılıyor olması,

- Merkezi bir Pazar anlayışının olmaması, 
- Çok fazla küçük çaplı işletmenin olması,

- Üretim miktarı ve ürün kalitesinin kontrollü olmaması ve bu kriterlerin tamamen doğal çevrenin sundukları ile sınırlanması,

- Tüm sağlayıcılar arasında rekabetin tırmanmasidir ${ }^{17}$.

$\mathrm{Bu}$ kriterler en gelişmiş Avrupa ülkelerinin genel sorunlarıdır. Bu sorunların tamamını aşabilmiş Avrupa ülkesi bulunmadığından, bölgedeki ihtiyacı karşılayacak üretim yetersizdir ve dışa bağımlıdır. Bu bağlamda Yeni Zelanda ve Avustralya gibi çok uzak ülkelerden bile ihracat yapılmak zorunda kalınmaktadır. Avrupa'nın en büyük, dünyanın ikinci büyük midye üreticisi İspanya'dır (180 bin-250 bin ton/y1l) ${ }^{17}$. İspanyada yetiştirilen Akdeniz midyesi canlı, dondurulmuş ve önemli kısmı lokal konserve şirketlerine gönderilir. İspanya'dan başka diğer üreticiler (hem avcıllk hem üretim, farklı türlerde); Fransa, İrlanda, Hollanda, Danimarka, İngiltere ve Almanya'd ${ }^{1}{ }^{17}$.

Midyenin en fazla satın alınan biçimi taze midyedir. Taze/canlı midyenin pazarda önemli bir yeri vardır. Bununla birlikte midye değer kazandırabilecek bir üründür. İşlenerek ticari değeri arttırılabilir. Bu amaçla hem perakende satışta hem de hazır yemek segmentinde; boyutuna göre sınıflandırılmış, temizlenmiş, ayıklanmış, paketlenmiş, yemeye hazır kaplamalarla kaplanmış veya yemeye hazır porsiyonlanmış (1sıt-ye) olarak pazarlanabilir.

İşlenmiş midyenin ticari yayılımı (Avrupa birliği kodlariyla):

1- Canlı, taze ya da soğuk muhafazalı kabuklu ya da kabuksuz midye: CN Code 030731

- Canlı, taze ya da soğuk muhafazalı kabuklu ya da kabuksuz midye, Mytilus spp.: CN Code 03073110
2- Hem kabuklu hem kabuksuz midyeler; dondurulmuş, tuzlanmış veya salamura içinde: $\mathrm{CN}$ Code 030739

- Hem kabuklu hem kabuksuz midyeler; dondurulmuş, tuzlanmış veya salamura içinde, Mytilus spp.: CN Code 03073910

3- Hava geçirmez kutularda korunmuş, hazırlanmış midyeler: CN Code 16059011

4- Diğer kutularda korunmuş, hazırlanmış midyeler: CN Code $16059019{ }^{17}$.

Dünya genelinde dondurulmuş midyelere olan talep son yıllarda artmıştır. Bu durum iki şekilde açıklanabilir.

- Birincisi kabuğu ayıklanmış, tüketime hazır dondurulmuş ürünlerin oldukça kolaylık sağladığı yaygın biçimde fark edilmiştir. Hazır yemek sektöründe kabuk ayıklama işlemi olmaksızın donuk midye etlerinin kullanımı iş gücünü düşürerek ekonomik çıktılar azaltılmıştır. Dondurulmuş midye, işleme endüstrisi tarafindan daha fazla tercih edilir.

- İkincisi ise dondurulmuş ürünlerde mikroorganizmaların pek çoğunun inaktive olması, vejatatif mikroorganizmaların ölmesi ve enzimlerin inaktivasyonudur.

Dondurulmuş ürünler uzun mesafede transfer edilebilir ve raf ömrü uzar ${ }^{20}$. Hazır gıda sektörü, kentleşme, gelir düzeyindeki değişimler, uzun çalışma saatleri ve kadının iş hayatına daha aktif katılımı nedeniyle gelişmiştir. Gıda ihtiyacını karşılamada geleneksel gıdaların yanı sıra yeni ürünler üreten sektör, mevcut ürünlerin güvenli ve sağlıklı biçimde paketlenerek yemeye hazır biçimde tüketicinin hizmetine sunmaktadır. Bununla birlikte hazır gida sektörü, sadece kayıtlı ve kontrollü firmalardan oluşmamaktadır. Bunlar dışında sokakta satılan veya kontrolü sağlanmayan hazır gıda 
sektörü parçaları da mevcuttur. Bu parçaların en önemli dezavantajı sanitasyon koşullarının takip edilememesi ve bazı gıda kaynaklı zehirlenmeler ve hastalıklara neden olabilmeleridir. Tüm bu nedenlerle ayıklanmış ve paketlenmiş donuk midyelere ve bu midyelerle işlenecek hazır midye yemeklerine (ready-to-eat) olan talep artmaya devam edecektir.

Sonuç olarak; hazır gıda sektöründe midye dolmanın potansiyelinin yüksekliği açıkça ortaya konmuştur. Bu potansiyelin en aktif biçimde değerlendirilmesinin ise midye yetiştiriciliğinin artması ve bunu takiben midye işlemenin fazlalşması, midye işlemenin ise daha yüksek kayıtlılığa erişmesinin gerekliliği vurgulanmıştır.

\section{KAYNAKLAR}

1. Parmalee, P.W. ve Klipper, W.E., 1974. Freshwater mussels as a prehistoric food resource. American antiquity, 39:3, 421-434.

2. Terzi, G. Gücükoğlu, A. Çadırcı, Ö. Uyanık, T. ve Alişarl1, M. 2015. Serotyping and antibiotic susceptibility of Listeria monocytogenes isolated from ready-to-eat foods in Samsun, Turkey. Turkish Journal of Veterinary and Animal Sciences, 39:211217.

3. Bingöl, E.B. Çolak, H. Hampikyan, H. ve Muratoğlu, K. 2008. The microbiological quality of stuffed mussels (Midye Dolma) sold in Istanbul. British Food Journal, 110(11): 1079 - 1087.

4. Özel İhtisas Komisyonu Raporu 2014. Su Ürünleri. ISBN 978-605-4667-67-3 YAYIN NO: KB: 2871 ÖİK: 721.

5. TÜİK 2015. Su ürünleri istatistikleri. T.C. G1da Tarım ve Hayvancılık Bakanlığı, Balıkçılık ve Su Ürünleri Genel Müdürlügü̈, Mart 2015.

6. TÜIK 2018. Su ürünleri istatistikleri. T.C. G1da Tarım ve Hayvancılık Bakanlığı, Balıkçılık ve Su Ürünleri Genel Müdürlüğü, Ağustos 2018.

7. Görkem, O. 2015. Franchising Sistemi Uygulanan Fast Food İşletmelerinde Örgütsel Bağl1lık: Denizli Örneği. Journal of Business Research Turk, 7(1):267-
279.

8. Güler, S. 2010. Türk Mutfak Kültürü ve Yeme İçme Alışkanlıkları. Dumlupınar Üniversitesi Sosyal Bilimler Dergisi, 26: 24-30.

9. Acar Tek, N. ve Sürücüoğlu, MS. 2014. Basılmış olan ilk Türk yemek kitabı "Melceü't-Tabbahin". Gazi Türkiyat, 14:225-229.

10.Castellani, V. 2004. Les cuisines de rue. ISBN: 9782742749324

11.Şireli, UT ve Gücükoğlu, A. 2008. Prevalence and Antibiotic Resistance of Listeria Spp. Isolated from Ready-to-Eat Foods in Ankara. Turkish Journal of Veterinary and Animal Sciences, 32(2): 131-135.

12.Göksoy, E.Ö. Kırkan, Ş. ve Kaya, O. 2006. Comparison of Polymerase Chain Reaction and Conventional Methods for the Diagnosis of Listeria monocytogenes in Stuffed Mussels. Turkish Journal of Veterinary and Animal Sciences, 30:229-234.

13. Terzı G, Gucukoglu A, Cadırc1 O, Kevenk TO ve Alisarl1 M. 2013. Effects of Chitosan and Lactic Acid Immersion on the Mussels" Quality Changes During the Refrigerated Storage. ournal of the Faculty of Veterinary Medicine, Kafkas University, 19 (2): 311317, 2013. DOI: 10.9775/kvfd.2012.7779.

14.Doğan Halkman, HB ve Halkman, AK. 2004. Gidalarda Escherichia coli Olmayan Fekal Koliformlar Üzerine bir Araştırma. Orlab On-Line Mikrobiyoloji Dergisi, 2(2):1-5.

15.Ateş, M. Özkızılcık, A. ve Tabakoğlu, C. 2011. Microbiological Analysis of Stuffed Mussels Sold in the Streets. Indian Journal of Microbiology, 51(3):350-354.

16.Ulusoy, Ş. ve Özden, Ö. 2011. Preservation of Stuffed Mussels at $4^{\circ} \mathrm{C}$ in Modified Atmosphere Packaging. Journal of Aquatic Food Product Technology, 20:3, 319-330.

17.Monford, 2000. The French Market for Mussels: Dominant Features, Competitive Forces and Prospects. SNF-REPORT NO. 05/2000. Centre for Fisheries Economics Report No. 62. Foundation for Research in Economics and Business Administration, 
Bergen, Fransa.

18.Alçiçek Z., Balaban M.O., 2015a. Characterization OfGreen Shelled Mussel Meat. Part I: Quantification Of Color Changes During Brining And Liquid Smoke Application Using Image Analysis. JOURNAL OF AQUATIC FOOD PRODUCT TECHNOLOGY, vol.24, pp.2-14.

19.Alçiçek Z., Balaban M.O., 2015b. Characterization Of Green Lipped Mussel Meat. Part II: Changes In Physical Characteristics As A Result Of Brining And Liquid Smoke Application. JOURNAL OF AQUATIC FOOD PRODUCT TECHNOLOGY, vol.24, pp.15-30.

20.Huss, H.H. 1995. Quality and quality changes in fresh fish. FAO Fisheries technical paper . No. 348, 195p pp. Roma: FAO.15. Shomar B.H, Müler G, Yahya A, 2005. Seasonal variations of chemical composition of water and bottom sediments in the wetland of Wadi Gaza, Gaza Strip, Wetlands Ecology and Management, 13: 419-431. 